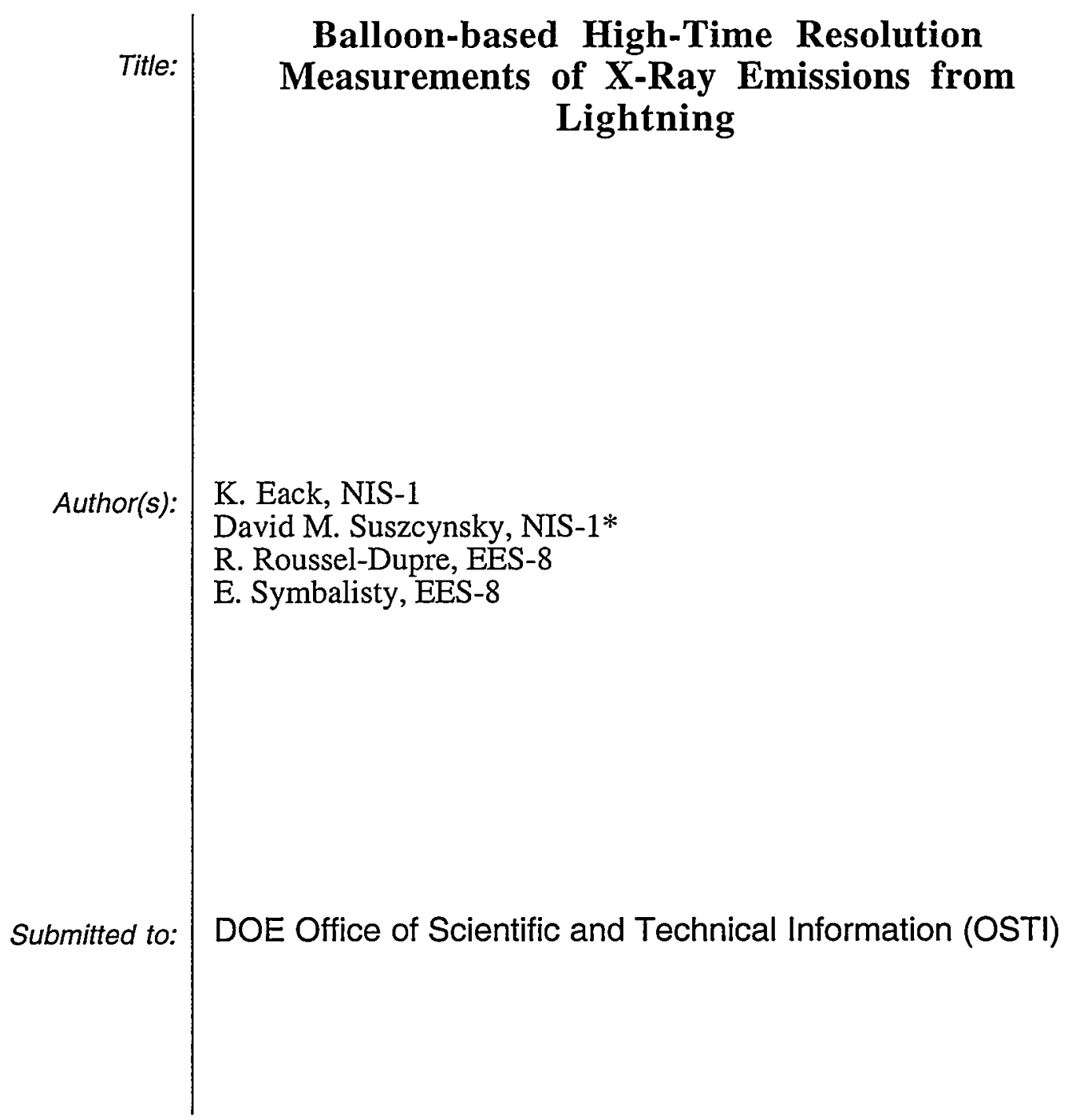

Los Alamos National Laboratory, an affirmative action/equal opportunity employer, is operated by the University of California for the U.S. Department of Energy under contract W-7405-ENG-36. By acceptance of this article, the publisher recognizes that the U.S. Government retains a nonexclusive, royaltyfree license to publish or reproduce the published form of this contribution, or to allow others to do so, for U.S. Government purposes. Los Alamos National Laboratory requests that the publisher identify this article as work performed under the auspices of the U.S. Department of Energy. Los Alamos National Laboratory strongly supports academic freedom and a researcher's right to publish; as an institution, however, the Laboratory does not endorse the viewpoint of a publication or guarantee its technical correctness. 


\section{DISCLAIMER}

This report was prepared as an account of work sponsored by an agency of the United States Government. Neither the United States Government nor any agency thereof, nor any of their employees, make any warranty, express or implied, or assumes any legal liability or responsibility for the accuracy, completeness, or usefulness of any information, apparatus, product, or process disclosed, or represents that its use would not infringe privately owned rights. Reference herein to any specific commercial product, process, or service by trade name, trademark, manufacturer, or otherwise does not necessarily constitute or imply its endorsement, recommendation, or favoring by the United States Government or any agency thereof. The views and opinions of authors expressed herein do not necessarily state or reflect those of the United States Government or any agency thereof. 


\section{DISCLAIMER}

Portions of this document may be illegible in electronic image products. Images are produced from the best available original document. 


\title{
Balloon-based High-Time Resolution Measurements of X-Ray Emissions from Lightning
}

\author{
Kenneth Eack, David M. Suszcynsky*, Robert Roussel-Dupre, Eugene M. D. Symbalisty
}

\begin{abstract}
This is the final report of a three-year, Laboratory-Directed Research and Development (LDRD) project at the Los Alamos National Laboratory (LANL). The project consisted of a series of balloon flights to collect high-timeresolution $\mathrm{X}$-ray and electric-field-change measurements in thunderstorms in order to validate the existence of the runaway air-breakdown mechanism during lightning and/or sprite production. The runaway air-breakdown mechanism is currently the leading theory to account for unexplained balloon and aircraftbased measurements of x-ray enhancements associated with sprites. Balloonborne gamma-ray and electric-field_change instruments were launched into a daytime summer thunderstorm. $\bar{A}$ greater than three-fold increase in the gamma-ray flux was observed as the balloon descended through a thunderstorm anvil where a strong electric field was present. These observations suggest that gamma-ray production in thunderstorms may not be as uncommon as previously believed.
\end{abstract}

\section{Background and Research Objectives}

Attempts to measure gamma-ray emissions from thunderstorms have been made since 1925, when C.T.R. Wilson first speculated that strong thunderstorm electric fields might accelerate free electrons that would, in turn, produce significant bremsstrahlung emissions (Wilson, 1926). Early efforts to detect gamma-ray emissions from thunderstorms were inconclusive, primarily because of technical limitations and the difficulty of making unambiguous in-situ measurements in an active electrical environment (see e.g. Suszcynsky et al., 1998). In particular, most efforts lacked electric-field information that can be used to relate observed gamma-ray increases to either strong electric fields or large transients in the electric field. Only recent aircraft-based (Parks et al., 1981; McCarthy and Parks, 1985) and balloonbased (Eack et al., 1996a; Eack, 1997) measurements have provided strong evidence for gamma-ray production in thunderstorms, relying heavily on advances in electronics and thunderstorm ballooning techniques.

The production of gamma rays in the atmosphere is governed by the production of energetic charged particles (electrons, positrons, muons, etc.). Cosmic rays and their interactions with the atmosphere are significant sources of energetic charged particles (Smart, 1985). The particles produce a gamma-ray background that is strongest at an altitude near $15 \mathrm{~km}$ above mean sea level (MSL)

*Principal Investigartor, e-mail: dsuszcynsky@lanl.gov

RECEIVED

DEC 132000 
An increase in the gamma count rate could occur from localized variations in the cosmic-ray and cosmic-ray-secondary flux (Smart, 1985), or by strong electric fields in the environment of a thunderstorm. Two basic theories have been proposed that use the electric field of a thunderstorm to increase the local population of energetic electrons. The first theory is based on Wilson's original hypothesis that free electrons are accelerated by the thunderstorm electric field and, as a result, produce gamma rays. The presence of an electric field increases the mean-free-path of the electrons, allowing the electrons to travel a greater distance. In localized regions, this will add additional electrons to those that are produced locally and produce an increase in the energetic electron population (McCarthy and Parks., 1992). The second theory is the runaway electron hypothesis first proposed by Gurevich et al. (1992). It requires a cosmic-ray produced "seed" electron of about $1 \mathrm{MeV}$ to initiate an electron avalanche. Additional electrons are produced when these seed electrons "knock-off" electrons from molecules. If the local electric field is strong enough, both the original seed electron and the "knock-off" electron may gain more energy from the field (on average) than is lost from collisions with molecules. This process produces an avalanche of energetic electrons that can proceed in electric fields with magnitudes a factor of ten less than is required to initiate conventional dielectric breakdown in air.

As noted by McCarthy and Parks (1992), the Wilson mechanism for sustaining energetic electrons in thunderstorm electric fields cannot produce sufficient bremsstrahlung emission to account for the magnitude of gamma-ray increases that they measured. In fact, to date the only viable theory that accounts for gamma-rays in association with thunderstorm electricity is the runaway-electron hypothesis. This mechanism has been studied theoretically using detailed kinetic calculations (Symbalisty et al., 1998) and has been used to develop detailed models for high-altitude discharges (TLE) (Taranenko and Roussel-Dupre, 1996; Roussel-Dupre et al., 1998a; Yukhimuk et al., 1999). More recently Roussel-Dupre et al. (1998b), have also invoked the runaway mechanism in models of intra-cloud lightning.

\section{Importance to LANL's Science and Technology Base and National R\&D Needs}

This project was important to LANL's science and technology base in that it utilized and further developed LANL's expertise and capabilities in the areas of atmospheric and ionospheric science. Such competencies are useful for advancing basic scientific knowledge and for enhancing the laboratory's reputation of excellence in carrying out quality scientific, technical, and programmatic studies. 
In particular, it is essential to maintain these competencies for programmatic purposes, in this case, to maintain our ability to measure, model, and understand deviations from the normal gamma-ray background and electrical environment of the atmosphere and ionosphere. Effective discrimination between these naturally occurring transients and manmade transients associated with nuclear detonations is an essential component in our mission to monitor and verify nuclear detonations from space-based platforms.

\section{Scientific Approach and Accomplishments}

The instrumentation consisted of a gamma-ray detector, an electric field change sensor, a data acquisition system, and a spread-spectrum telemetry system housed in a 10-inch aluminum sphere. Total weight was approximately two kilograms. The data acquisition system used a 386SX class processor that allowed for a sampling rate of $15 \mathrm{kHz}$. Previous balloon gamma-ray measurements used a sample rate of $4 \mathrm{~Hz}$ (Eack et al., 1996). This improvement in temporal resolution allowed us to associate detected gamma emissions with other events, such as electric-field changes. This resolution was required in order to associate a gamma-ray event (if any) to a TLE that is observed by ground-based instrumentation.

An isolated 3-inch diameter sensing plate faced downward for the field-change sensor. The field-change instrument had a dynamic range of $+/-9000 \mathrm{~V} / \mathrm{m}$. More details on, as well as data from, this instrument can be found in Beasley et al. (2000).

The gamma detector was similar in design to that described by Eack et al. (1996), except for a thicker $\mathrm{NaI}$ scintillation crystal that was used to improve the gamma-ray detection efficiency at higher energies. This increased the detection range of a gamma-ray event due to the longer mean free path of gamma rays with higher energies. The detector covered the energy range from $60 \mathrm{keV}$ to $300 \mathrm{keV}$ in three channels (60-100, 100-200 and 200-300 keV).

The instrument was a triggered system with the primary trigger provided by the gamma-ray detector. The trigger criterion was set so that 15 counts had to be observed within an interval of 300 microseconds. If no gamma-ray trigger was received within five minutes of the previous trigger, the electric-field-change instrument could also trigger the system if the field-change exceeded $+/-500 \mathrm{~V} / \mathrm{m}$. The data acquisition system collected $400 \mathrm{~ms}$ of pre-trigger data and another $400 \mathrm{~ms}$ of post-trigger data.

The instrument was launched at 0010 UT on June 19, 1998 near Elmore City, Oklahoma. During the ascent, 12 triggers were recorded, all of which were due to the electric-field-change instrument. After reaching a peak altitude of $22.6 \mathrm{~km}$ at $0105 \mathrm{UT}$ the balloon burst and the instrument began to descend. Ten additional triggers were recorded during the descent, two of which were initiated by the gamma ray instrument. 
The flight ended at 0139 UT when the instrument landed. No matter which instrument triggers the data acquisition system, both the gamma-ray and the electric-field-change data are recorded. Because of this, and the relatively frequent triggers by the electric-field instrument during both ascent and descent, the gamma detector was able to record a vertical profile of the gamma-ray background similar to that observed on previous balloon flights (Eack, 1997). The maximum background count rate occurred at an altitude of about $15 \mathrm{~km}$ MSL (Figure 1) as with previous cosmic ray observations (McCarthy et al., 1992).

The two triggers caused by increased gamma emissions (labeled 22 and 23 on Figure 1), which occurred during the descent, indicated a much higher count rate than the background observed at the same altitude during the ascent. The two triggers occurred 10 seconds apart, which is approximately the re-arm time of the instrument. Except for these two events, the gamma count rate profiles for the ascent and descent were essentially the same (Figure 1).

At the time of triggers 22 and 23, the balloon was at about $14 \mathrm{~km} \mathrm{MSL}$ and descending with a vertical velocity of about $30 \mathrm{~m} / \mathrm{s}$. At this time, the WSR-88D radar for Oklahoma City (KTLX) indicated an anvil at the same position as the balloon, with reflectivities between 10 and $20 \mathrm{dBZ}$ at $13.5 \mathrm{~km}$ MSL. The anvil was from a complex of thunderstorms located $75 \mathrm{~km}$ southeast of the balloon position.

From the available observations it is not possible to determine with absolute certainty if the two measurements of gamma-ray emissions were two independent bursts or pulses such as those observed by Eack et al. (1996b) or two measurements of a long-duration gamma event as reported by Eack et al. (1996a) and Eack (1997). However, there is additional evidence to support the belief that the two events represent long-duration gamma emissions caused by strong electrostatic fields in the anvil.

Previous measurements of the (DC to $10 \mathrm{~Hz}$ ) electric field in the anvil of thunderstorms have shown that anvils can be highly electrified (Marshall et al., 1989; Macgorman and Rust, 1998). More importantly, another balloon flight launched approximately one hour after the launch of this flight observed the electric field at $13.5 \mathrm{~km} \mathrm{MSL}$ (the altitude of the enhanced gamma ray measurements) to be greater than $40 \mathrm{kV} / \mathrm{m}$ (D. MacGorman, private communication). This is comparable to the threshold field of $44 \mathrm{kV} / \mathrm{m}$ for the runaway electron hypothesis for this altitude. There was no electric-field change of consequence at these times, indicating that the gamma-ray production was not due to a transient electric field. Furthermore, the facts that the time separation between the two triggers was approximately equal to the rearm time, and that over each of the 0.8 second records the gamma count rate was nearly constant (Figure 2), provide additional evidence that the elevated gamma emissions were continuous during that period, and thus likely to have been caused by strong, but slowlyvarying electric fields. 
This observation is consistent with those made at $5 \mathrm{~km}$ MSL in mesoscale convective systems by Eack et al. (1996a) and Eack (1997). In their observations, increased gamma-ray count rates were observed in regions with electric fields of both polarities that had magnitudes comparable to the threshold required by the runaway-electron hypothesis. None of the gammaray measurements they made had random variations in the gamma-ray background greater than 2s (Poisson statistics) from average. The gamma-ray increases shown here are nearly $40 \mathrm{~s}$ above the background measured during this flight. The intensity of secondary particles in the core of a cosmic ray shower can be orders of magnitude above the average intensity, but only for a few microseconds (Smart, 1985).

In the cases presented by Eack et al. (1996a) and Eack (1997), as well as this one, comparison with theoretical predictions for the gamma-ray flux and spectral content is currently impossible. Because the distance between the instrument and the production region is unknown, we cannot estimate the effects of the atmosphere on the flux and spectrum due to absorption and Compton scattering. Even if this distance was known, the electric field in the production region is unknown and the runaway electron models are sensitive to the electricfield strength as well as the vertical distance over which the electric field exceeds the runaway threshold (Symbalisty et al., 1998).

\section{Concluding Remarks}

A flight of an instrumented balloon designed to test the runaway breakdown hypothesis in and above thunderstorms has provided additional evidence that gamma ray production does occur in the thunderstorm environment. The observed increase in gamma-ray emission appears to be due to an electric field in the anvil of a thunderstorm, and is different from previous observations of gamma rays in thunderstorms (Eack et al, 1996a; Eack, 1997) in that they were made in the stratiform region of large mesoscale convective systems at much lower altitudes. The measurements reported here indicate that the production of gamma rays by thunderstorms is not limited to isolated regions near the main charge centers of large thunderstorm complexes. Finally it is important to note that in the limited number of gamma-ray observations recently made in thunderstorms by balloon, the majority of them have provided evidence for gamma-ray production by strong electric fields. Because of these observations, we conclude that it is likely that this phenomenon is a more common occurrence in thunderstorms than previously recognized. 


\section{Publications}

1. Eack, K. B., Suszcynsky, D. M., Beasley, W. H., Roussel-Dupre, R., Symbalisty, E. M. D., "Gamma-ray emissions observed in a thunderstorm anvil," Geophysical Research Letters, 27, 185-188 (2000).

\section{References}

Beasley, W.H., Eack, K. B., Morris, H. E., Rust, W. D., and MacGorman, D. R., "Electricfield changes of lightning observed in and above thunderstorms," Geophysical Research Letters, 27, 181-184 (2000).

Eack, K.B., "Balloon-borne X-ray spectrometer for detection of X-rays produced by thunderstorms," Reviews of Scientific Instruments, 67, 2005-2009 (1996).

Eack, K.B, Beasley, W. H., Rust, W. D., Marshall, T. C., Stolzenburg, M., "Initial results from simultaneous observations of x rays and electric fields in a thunderstorm," Geophysical Research Letters, 101, 29637-29640 (1996a).

Eack, K.B. Beasley, W. H., Rust, W. D., Marshall, T. C., Stolzenburg, M., "X-ray pulses observed above a mesoscale convective system," Geophysical Research Letters, 23, 29152918 (1996b).

Eack, K.B., "Observations of $\mathrm{x}$ rays produced by strong electric fields in thunderstorms," Ph.D. Dissertation, 100 pp., University of Oklahoma (1997).

Gurevich, A. V., Milikh, G. M., and Roussel-Dupre, R., "Runaway electron mechanism of air breakdown and preconditioning during a thunderstorm," Physics Letters A, 165, 463-468 (1992).

MacGorman, D.R., Rust, W. D., "The Electrical Nature of Storms", Oxford University Press, 422 pp. (1998).

Marshall, T.C., Rust, W. D., Winn, W. P., and Gilbert, K. E. " "Electrical structure in two thunderstorm anvil clouds," Geophysical Research Letters, 94, 2171-2181 (1989).

McCarthy, M.P., and Parks, G.K., "Further observations of X-rays inside thunderstorms," Geophysical Research Letters, 12, 393-396 (1985).

McCarthy, M.P. and Parks, G. K., "On the modulation of x ray fluxes in thunderstorms," Geophysical Research Letters, 97, 5957-5864 (1992).

Parks, G.K., Mauk, B. H., Spiger, R., and Chin, J., "X-ray enhancements detected during thunderstorm and lightning activities," Geophysical Research Letters, 8, 1176-1179 (1981).

Roussel-Dupre, R., Symbalisty, E., Taranenko, Y., and Yukhimuk, V., "Simulations of highaltitude discharges initiated by runaway breakdown," Journal of Atmospheric and Solar Terrestrial Physics, 60, 917-940 (1998a).

Roussel-Dupre, R., Symbalisty, E., and Yukhimuk, V., "Initiation of intra-cloud discharges by runaway air breakdown," EOS Transactions, 79, F136 (1998b). 
Suszcynsky, D.M., Roussel-Dupre, R., and Shaw, G., "Ground-based search for X-rays generated by thunderstorms and lightning," Journal of Geophysical Research, 101, 2350523516 (1996).

Smart. D.F., and Shea, M. A., "Galactic cosmic radiation and solar energetic particles", in Handbook of Geophysics and the Space Environment, edited by A.S. Jursa, Air Force Geophysics Laboratory (1985).

Symbalisty, E. M. D., Roussel-Dupre, R., and Yukhimuk, V., "Finite volume solution of the relativistic boltzmann equation for electron avalanche studies," IEEE Transactions on Plasma Science, 26, 1575-1582 (1998).

Taranenko, Y. and Roussel-Dupre, R., "High altitude discharges and gamma ray flashes: A manifestation of runaway air breakdown," Geophysical Research Letters, 23, 571-574 (1996).

Wilson, C.T.R, "The acceleration of beta-particles in strong electric fields such as those of thunderclouds," Proceedings of the Cambridge Philosophical Society, 22, 534-538 (1926).

Yukhimuk, V., Roussel-Dupre, R., and Symbalisty, E. M. D., "On the temporal evolution of red sprites: Runaway theory versus data," Geophysical Research Letters, 26, 679-682 (1999).

\section{Figure Captions}

Figure 1. Vertical profile of gamma-ray count rate (sum of all energy bins) constructed from 24 triggers captured in-flight. Triggers 1-5 occurred on the ground during preparation for flight and are not shown on this plot.

Figure 2. High-time-resolution (1 millisecond) plots of the gamma count rate (sum of all channels) for triggers 22 (upper) and 23 (lower). 


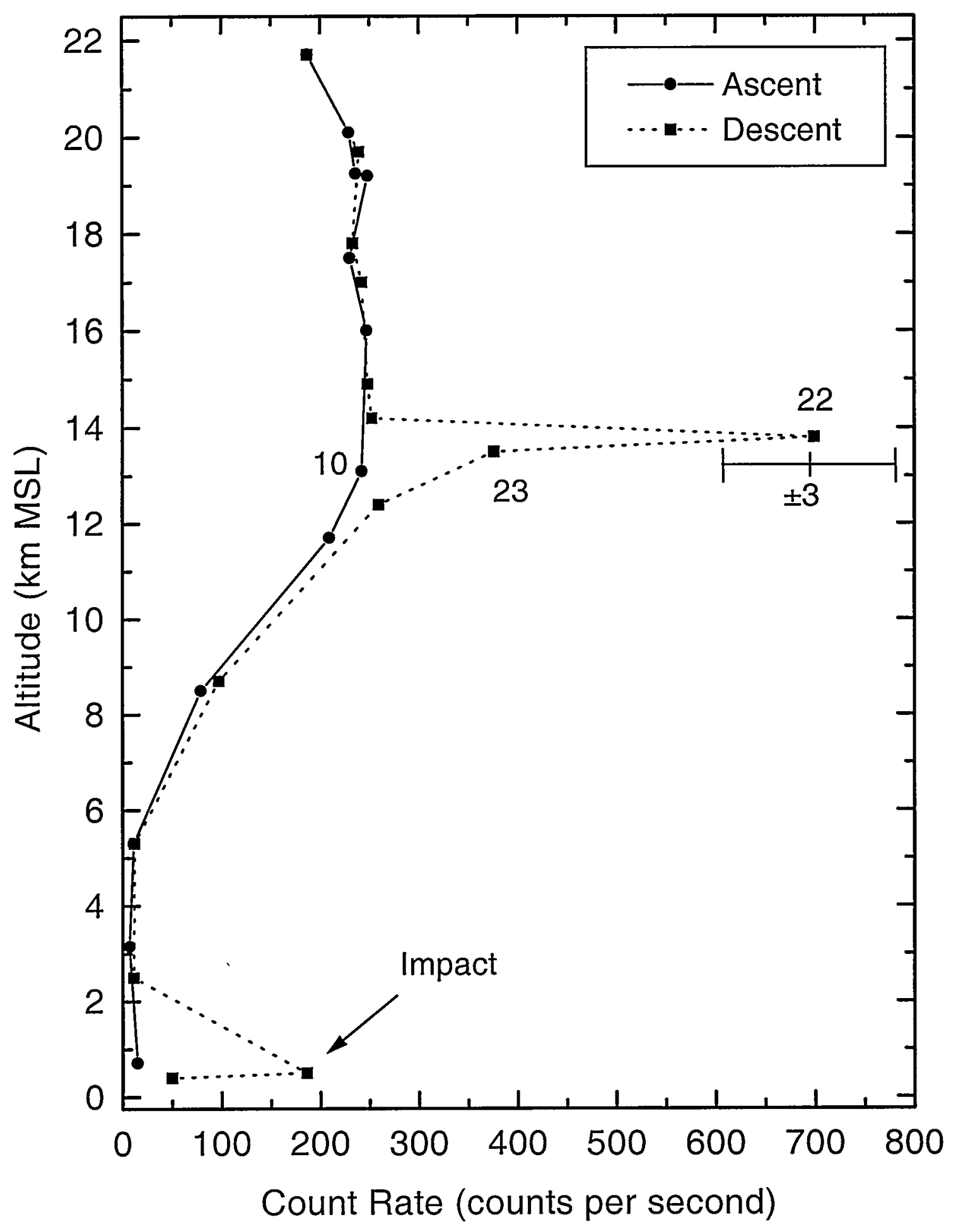

Fig. 1 


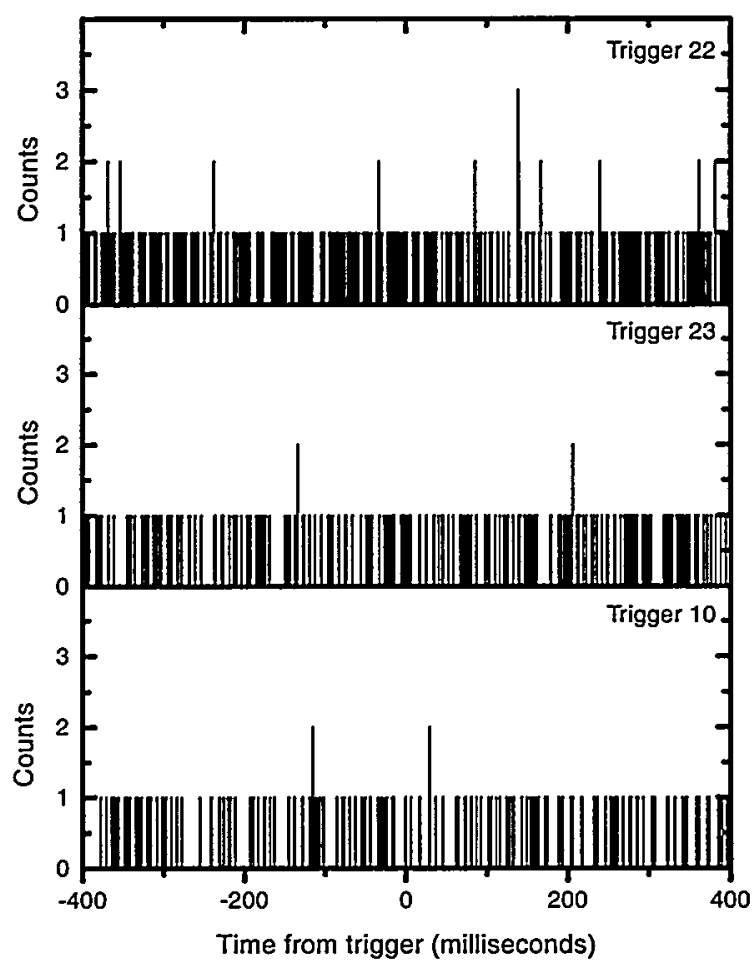

Fig. 2 